\title{
Кашинцева О.А. \\ Привлечение к исследовательской деятельности студентов-бакалавров направления подготовки 44.03.05 «Педагогическое образование»
}

\author{
ФГБОУ ВО «Череповеикий государственный университет»
} (Россия, Череповеи)

doi: $10.18411 / \mathrm{lj}-06-2021-176$

\section{Аннотация}

В статье рассматривается необходимость вовлечения студентов, будущих учителей математики и информатики, в исследовательскую деятельность. Отдельное внимание уделено проблемам при занятиях со студентами. Приводятся примеры введения элементов научных исследований в учебный процесс на занятиях по математическим дисциплинам.

Ключевые слова: Математическое образование, компетенции учителя, исследовательская деятельность студентов, исследовательский метод обучения.

\section{Abstract}

The article discusses the need to involve students, future teachers of mathematics and computer science, in research activities. Special attention is paid to the problems in the classroom with students. Examples of the introduction of elements of scientific research in the educational process in the classroom in mathematical disciplines are given.

Keywords: Mathematical education, teacher's competence, students ' research activity, research method of teaching.

В век бурного развития IT-технологий, перехода к новому технологическому укладу невозможно представить ни одну сферу нашей жизни, на которую бы ни оказали влияние инновационные процессы и открытия, в том числе и систему отечественного образования.

Мы находимся в окружении компьютерной и цифровой техники, развитие которой напрямую зависит от уровня математической подготовки специалистов. 2021 год был объявлен в России годом науки и технологий, а 2023 год может стать годом математики. Эту идею победителя Всероссийского конкурса «Учитель года 2020» М.Н. Гурова поддержал глава государства В.В. Путин. Для подготовки хороших специалистов различного профиля в любой области, не только в IT-сфере, стало необходимо глубокое базовое математическое образование, которое закладывается, начиная со школы. Это повлекло за собой повышение требований к качеству обучения учителей математики и информатики. Современные школы ждут молодых преподавателей не просто отлично знающих эти дисциплины, виртуозно владеющих методикой их преподавания, но и отличающихся инициативностью, гибкостью мышления, способностью к саморазвитию и самообразованию.

Эффективности решения будущими учителями профессиональных задач, творческой реализации полученных в университете знаний, умений и навыков содействуют занятия студентов научно-исследовательской деятельностью. Это «деятельность, которая имеет продуктивный характер, осуществляется в рамках образовательного процесса в вузе средствами познания в соответствии с логикой научного поиска, продуктом которой являются субъективно новые знания о самом исследуемом объекте или о конкретном» способе изучения [1].

Согласно новым ФГОСам высшего образования педагогов, готовность выпускников - бакалавров к осуществлению разнообразных видов деятельности, в том числе исследовательской, формирует «компетенции, связанные с развитым умением к анализу, исследованию, обобщению, адекватной оценкой явлений, событий, 
процессов» [2]. Следовательно, от успешности студента в исследовательской работе напрямую зависят его будущие профессиональные качества.

Основной задачей учебно-исследовательской деятельности является приобретение студентами навыков самостоятельной теоретической и экспериментальной работы, которые они получают при написании курсовых работ; участвуя в проектах, вузовских конкурсах, в студенческих научных конференциях университета (СНК).

Работая над проектом, будущие учителя математики и информатики самостоятельно приобретают новые знания из других наук: о нейронных сетях, специальных языках программирования, методах психологии и т.п. Это может стать полезным для их исследовательской и профессиональной работы в будущем, например, при разработке учебных программ или программ дополнительного образования (обучения компьютерной грамотности).

Для участия в СНК студенты под руководством преподавателя обычно изучают 1) дополнительный материал к рассматриваемому на занятиях в университете, например, вычисление «неберущихся» интегралов, типа интеграла Пуассона; 2) новый материал, который не будет рассматриваться в вузовском курсе математики, например, темы из дифференциальной геометрии, основ вариационного исчисления, абстрактной алгебры. При этом учащиеся не только должны самостоятельно разобраться в довольно сложном материале, но и объяснить его доступно и интересно участникам конференции.

Те студенты, которые выбрали себе траекторию развития «Наука и инновации», приобщаются к научно-исследовательской работе посредством участия в региональных и Всероссийских конкурсах и конференциях, таких как, например, Всероссийский конкурс студенческих научных работ по педагогике и психологии «Образование в эпоху перемен: проблемы и решения»; Молодежный научный форум «Молодые исследователи - регионам», Всероссийский конкурс УМНИК (Участник Молодежного Научно-Исследовательского Конкурса) Фонда содействия инновациям и др.

К сожалению, у преподавателей возникают проблемы при привлечении студентов к исследовательской деятельности, связанные с низким уровнем их школьной математической подготовки и нежеланием большинства студентов принимать участие в дополнительных мероприятиях. Но самой большой проблемой является то, что студенты не умеют учиться самостоятельно, что отмечают все преподаватели вузов [3].

В университете было проведено исследование среди 53 будущих педагогов, студентов разных курсов, показавшее реальное количество обучающихся, нацеленных на получение компетенции исследовательской работы. Студентам предлагалось оценить себя по двум основным критериям: 1) наличие мотивации на занятия исследовательской деятельностью (есть/нет), 2) готовность и умение учиться самостоятельно (есть/нет): умение работать с новым материалом, проникать в суть, усваивать и осваивать его, применять к решению задач. В среднем мотивацией и готовностью к самостоятельному обучению обладают только $23 \%$ студентов от общего числа. Чем старше курс - тем процент выше. Остальные разделились на три группы: могут (по мнению студентов), но не хотят - 33\%, не могут и хотят - $15 \%$, не могут и не хотят - 29\%. Цифры преподавателей, которые также давали оценку количеству студентов, заинтересованных в занятиях научно-исследовательской работой, получились соответственно такие: $25 \%-50 \%-15 \%-10 \%$.

Стать хорошим учителем, не обладая этими основными факторами образовательной успешности - невозможно. Задача преподавателя, чтобы все студенты приобрели исследовательские умения и навыки, особенно это актуально в настоящее время, когда количество аудиторных часов сократилось наполовину. Можно 
заинтересовать студентов, дав им для изучения интересные увлекательные темы, например, про точки Лагранжа, фракталы, создание математической модели машины времени TARDIS и т.п. Но в связи с вышесказанным основным направлением в развитии студенческой науки на сегодняшний день является введение элементов научных исследований в учебный процесс. При этом применяется исследовательский метод - это «обусловленная принципами обучения система правил подготовки учебного материала и организации преподавателем самостоятельной работы учащихся по решению проблемных заданий с целью усвоения ими новых понятий и способов действий и развития у них интеллектуальной и других сфер» [2].

Сочетать научный поиск студента с его обучением удобно при изучении сложных, но очень важных тем, например, темы «Пределы». Строгое математическое определение предела довольно громоздко и трудно для восприятия. При этом «на языке предела» формулируются такие основополагающие понятия математики как производная и интеграл. Слова «неограниченно возрастает» и «стремится к числу или бесконечности» понятны каждому студенту, когда речь идет о наглядных свойствах графика. Понимание использования этих слов в математических рассуждениях и вычислениях, формулировка значения данных выражений на языке чисел стали целью исследования студентами понятия предела.

Для достижения цели перед бакалаврами преподавателем были поставлены задачи: 1) изучить понятия «ловушки» и «кормушки» для последовательности, 2) рассмотреть геометрическое толкование определения предела, 3) разобрать пределы последовательностей чисел и геометрических объектов, 4) исследовать свойства конкретных последовательностей, 5) проанализировать аксиомы и теоремы БольцаноВейерштрасса, 6) доказать предложенные утверждения и теоремы. Студенты должны были вникнуть в сущность проблемы, рассмотреть ее со всех сторон; придерживаясь логических правил, самостоятельно найти решения задач. Например, такой: «С какой точностью нужно измерить длину экватора, чтобы вычислить объем Земли с точностью до 1 км $^{3}$, считая Землю идеальным шаром с радиусом 6400 км?» [4].

Умение доказывать очень важно для приобретения исследовательских компетенций. Среди предложенных студентам задач на доказательства были такие: 1) Докажите, что последовательность $x_{n}=\frac{10 n}{n^{2}+1}$ почти вся лежит в отрезке $[-0,001 ; 0,001] .2)$ Известно, что $\lim _{n \rightarrow \infty} x_{n}=0$. Могут ли в этой последовательности быть члены, большие 1000000? [4] 3) Докажите, что аксиома Больцано-Вейерштрасса не выполняется, если рассматривать только рациональные числа.

Достижение студентами цели работы способствовало не только лучшему пониманию темы «Пределы», но и развитию у них исследовательского типа мышления. Даже плохо успевающие студенты, которые выполнили не все предложенные задачи, отметили, что такие задания нужны, ведь они учат находить нужный материал, понять его суть, а приобретенные самостоятельно новые сведения способствуют развитию интереса к теме.

Включение в учебный процесс исследовательского метода во время дистанционного обучения в связи с пандемией коронавируса позволило студентам не только разобраться в лекциях и практических занятиях без «живого» общения с преподавателем, но и самостоятельно изучить дополнительные материалы для усвоения и закрепления темы. Поэтому в стенах вуза очень важно развить исследовательские умения обучающихся. «Я слышу - я забываю, я вижу - я запоминаю, я делаю - я понимаю», - гласит китайская поговорка. 
Исследовательская деятельность формирует положительную мотивацию студентов, будущих педагогов, к изучению математики, является необходимой составляющей их профессии. Учитель математики и информатики несомненно должен хорошо разбираться в своем предмете и компьютерных технологиях, стремиться развиваться и самообразовываться, чтобы быть интересным своим ученикам, чтобы замотивировать их на приобретение новых знаний, на желание учиться, чтобы уровень математического образования неуклонно повышался.

$$
* * *
$$

1. Ипполитова Н.В., Стерхова Н.С. Анализ понятия «Исследовательская деятельность студентов педагогического вуза» // Дискуссия. 2016. № 8(71). С. 112-120.

2. Валеева О.А., Железовская Г.И. Учебно-исследовательская деятельность как форма учебной работы // Вестник высшей школы. 2016. № 6. С. 53-56.

3. Ефанова Л. Д. Самостоятельная работа и самостоятельность студентов в вузе // Научнометодический электронный журнал «Концепт». - 2016. - T. 15. - C. 431-435. - URL: http://ekoncept.ru/2016/86989.htm. (дата обращения: 29.04.2021)

4. Кириллов А.А. Пределы. Издательство «Наука». Главная редакция физико-математической литературы, Москва, 1973, 96 стр. с илл.

\section{Кильметова Р.Р., Климатов Х.Г. \\ Риск-ориентированный подход при проведении выездных налоговых проверок: правовая основа и практика применения}

ФГБОУ ВО «СОГУ им. К.Л.Хетагурова»

(Россия, Владикавказ)

doi: $10.18411 / \mathrm{j}-06-2021-177$

\section{Аннотация}

В данной статье исследуются особенности специфики планирования выездных налоговых проверок с использованием риск-ориентированного подхода оценки налогоплательщиков. Изучаются результаты внедрения данного подхода на современном этапе.

Ключевые слова: налоговое право, налоговый контроль, рискориентированный подход, налоговое администрирование, выездная налоговая проверка, налоговое правонарушение.

\section{Abstract}

This article deals with the specifics of planning onsite tax audits using risk-based approach to assessing taxpayers. The results of the implementation of this approach at the present stage are studied.

Keywords: tax law, fiscal law, risk-based approach, the tax administration, onsite tax audit, tax offences.

Налоговая политика государства создается и осуществляется из необходимости создания и стимулирования положительных структурных изменений в экономике страны, снижения налоговой нагрузки не только с населения государства (физические лица), но и частных предприятий (юридические лица), а также для повышения эффективности налогового контроля.

Одним из важнейших условий эффективного функционирования налоговой системы и экономики государства является качественное налоговое администрирование. В свою очередь, налоговое администрирование неразрывно связано с налоговым контролем, целью которого является обеспечение своевременного и полного поступления налогов, взносов и других обязательных платежей в бюджет, а 